recommendations for the role of the RNS which were recently updated (Beech et al, 2019). This framework maps all of these requirements.

Objectives: This work supports the development of roles, improve access for patients and reduce. This document will act as a foundation for building sustainability and a more robust education and role development strategy. This work will strengthen rheumatology nursing and support all 4 UK nation's issues regarding recruitment, retention, sustainability, succession planning and benchmarking. Dissemination is key and we will work hard with stakeholders to ensure centralization of a nationally adopted framework. This abstract submission will increase dissemination opportunities.

Methods: Online data sources were searched for the most relevant and current evidence. Where research evidence wasn't available, existing and new knowledge was utilised from a consensus of clinical expert and patient opinions, several rounds of discussions took place virtually and face to face. RCN Rheumatology Nurse Forum Workshop attendees in June 2019 also answered a questionnaire to elicit views and demographic information regarding roles.

Results: The questionnaire results demonstrated 100\% (n37) agreement with the development of the framework and that only 2 respondents had completed a competency process. $60 \%$ were RNS. Of these $52 \%$ (n13) were band $6,47 \%$ (n9) were band 7 , and $1 \%$ were band 8 consultant nurses. The questionnaire highlighted the need to develop the framework. Results were fed back to the working party to inform the domains to be included.

Conclusion: Document will be at BSR 2020 having successfully submitted a session proposal and abstract. Evaluation will begin later in the year 6 to 12 months from launch. We will measure impact using a variety of methods including membership Facebook pages and the questionnaire at point of download request. We will measure where and how the competency is being used and adoption of the framework throughout the UK.

References:

[1] Beech B, Primdahl J, van Tubergen A, et al., (2019) 2019 update of the EULAR recommendations for the role of the nurse in the management of chronic inflammatory arthritis. Ann Rheum Dis. http://dx.doi.org/10.1136/ annrheumdis-2019-215458 (accessed 13 December 2019). Benner, P (1984) From novice to expert, excellence

[2] British Society of Rheumatology (2019) State of Play, London: BSR. Available at: www. rheumatology.org.uk/Portals/0/Documents/ Policy/BSR_State Of_Play_Scotland2018. pdf?ver=2019-03-11-094117-440 (accessed 13 December 2019).

[3] Martin N, Ibrahim F, Tom B, et al., (2017) Does intensive management improve remission rates in patients with intermediate rheumatoid arthritis? (the TITRATE trial): study protocol for a randomized controlled trial. Trials. 2017;18:591. doi.org/10.1186/s13063-017-2330-8.

Disclosure of Interests: Polly Livermore: None declared, Diana Finney Speakers bureau: Nordic

Abbvie, Julie Begum: None declared, Ruth Wyllie: None declared, Trish Cornell Employee of: Consultant Nurse for Abbvie, Helen Smith: None declared, Lisa Howie: None declared, Louise Parker: None declared

DOI: 10.1136/annrheumdis-2020-eular.6681

\section{AB1358-HPR DIAGNOSIS OF AXIAL SPONDYLOARTHRITIS: A PRIMARY UNMET EDUCATIONAL NEED FOR RHEUMATOLOGISTS}

W. P. Maksymowych ${ }^{1,2}$, L. Caplan ${ }^{3}$, A. Deodhar ${ }^{4}$, S. Dolatabadi ${ }^{5}$, M. Hwang ${ }^{6}$, A. Carlson ${ }^{7}$, K. Steed $^{8}$, A. Carapellucci ${ }^{2}$, J. Paschke ${ }^{2}$, L. S. Gensler ${ }^{9}{ }^{1}$ University of Alberta, Edmonton, Canada; ${ }^{2}$ CARE Arthritis, Edmonton, Canada; ${ }^{3}$ Rocky Mountain Regional VAMC, Aurora, United States of America; ${ }^{4}$ Oregon Health \& Science University, Portland, United States of America; ${ }^{5} \mathrm{Harbor}-U C L A$ Medical Center, Torrance, United States of America; ${ }^{6}$ Mc Govern Medical School at UTHealth, Houston, United States of America; ${ }^{7}$ University of Virginia, Charlottesville, United States of America; ${ }^{8}$ James J Peters VA Medical Center, New York, United States of America; ${ }^{9}$ University of California, San Francisco, San Francisco, United States of America

Background: Diagnosis of axial spondyloarthritis (axSpA) is challenging because of absent physical findings in early disease and the limited diagnostic performance of laboratory markers. Considerable reliance is placed on imaging of the sacroiliac joints (SIJ) but specialty training is primarily focused on interpretation of plain radiographic abnormalities.

Objectives: We aimed to identify what might be the primary unmet educational needs of rheumatologists completing fellowship training by using clinical and imaging data from an inception cohort of patients presenting with undiagnosed back pain. We hypothesized that concordance would increase after imaging is reviewed after the clinical data.

Methods: The diagnosis of axSpA was compared between local rheumatologists, axSpA experts and $\mathrm{pF}$ using clinical and imaging data from the multicenter Screening for Axial Spondyloarthritis in Psoriasis, Iritis, and Colitis (SASPIC) Study. In this inception cohort, patients $\leq 45$ years of age with $\geq 3$ months back pain undergo diagnostic evaluation by a local SASPIC rheumatologist, including imaging of the SIJ, who then records a global evaluation of presence/absence of axial SpA. This is done at 3 consecutive stages: 1.After the clinical evaluation. 2.After the results of labs (HLA B27, CRP) and radiography. 3.After review of the local MRI. In this exercise, 20 cases were selected from the SASPIC cohort and the rheumatologist global evaluations were removed from the eCRFs. Four experts in axSpA reviewed the clinical and imaging data in each eCRF and provided their global evaluations for stages 1, 2, and 3 of these 20 cases. Subsequently, $4 \mathrm{pF}$ rheumatologists conducted the same exercise blinded to the assessments of the local rheumatologist and experts in axSpA. Concordance (\% agreement) between the assessors was analyzed.

Results: Diagnosis of axSpA by the local SASPIC rheumatologist was made in $90 \%, 65 \%$, and $75 \%$ of cases after stages 1,2 , and 3 , respectively. Majority diagnosis of axSpA by experts was made in $84.2 \%$ (16/19), 57.9\% (11/19), and $63.2 \%(12 / 19)$, after stages 1,2 , and 3 , respectively. Majority diagnosis of axSpA by $\mathrm{pF}$ rheumatologists was made in $94.4 \%(17 / 18), 100 \%(16 / 16)$, and $93.8 \%$ (15/16). Concordance among experts and between experts and local SASPIC rheumatologists increased after review of imaging data. For pf-rheumatologists concordance with experts increased after review of imaging for 2 assessors and decreased for the other 2 assessors. For the latter, the primary reason for decrease in concordance with experts was false positive diagnosis of axSpA in $35 \%$ and $30 \%$ of the cases after review of the imaging.

Conclusion: A structured case-based and sequential evaluation of clinical and imaging data suggests a gap in the training of recently graduated rheumatologists, with over-interpretation of imaging leading to false positive diagnosis of axSpA.

\begin{tabular}{|c|c|c|c|}
\hline \multirow[t]{2}{*}{ Assessors } & \multicolumn{3}{|c|}{$\begin{array}{c}\text { Mean \% Concordance (range) for diag- } \\
\text { nosis of axSpA }\end{array}$} \\
\hline & Stage 1 & Stage 2 & Stage 3 \\
\hline Experts in axSpA & $64.2(45-80)$ & $75.8(65-85)$ & $84.2(70-95)$ \\
\hline Local rheumatologist vs Experts in axSpA & $73.8(70-80)$ & $83.8(80-85)$ & $83.8(80-90)$ \\
\hline pF rheumatologist 1 vs Experts consensus & 78.9 & 94.4 & 94.7 \\
\hline pF rheumatologist 2 vs Experts consensus & 89.5 & 61.1 & 68.4 \\
\hline pF rheumatologist 3 vs Experts consensus & 63.2 & 72.2 & 84.2 \\
\hline pF rheumatologist 4 vs Experts consensus & 89.5 & 66.7 & 68.4 \\
\hline
\end{tabular}

Disclosure of Interests: Walter P. Maksymowych Grant/research support from: AbbVie, Novartis, Pfizer, and UCB, Consultant of: AbbVie, Boehringer Ingelheim, Celgene, Eli Lilly, Galapagos, Janssen, Novartis, Pfizer, and UCB, Employee of: Chief Medical Officer of CARE Arthritis Limited, Speakers bureau: AbbVie, Janssen, Novartis, Pfizer, and UCB, Liron Caplan: None declared, Atul Deodhar Grant/research support from: AbbVie, Eli Lilly, GSK, Novartis, Pfizer, UCB, Consultant of: AbbVie, Amgen, Boehringer Ingelheim, Bristol Myer Squibb (BMS), El Lilly, GSK, Janssen, Novartis, Pfizer, UCB, Speakers bureau: AbbVie, Amgen, Boehringer Ingelheim, Bristol Myer Squibb (BMS), Eli Lilly, GSK, Janssen, Novartis, Pfizer, UCB, Soha Dolatabadi: None declared, Mark Hwang: None declared, Adam Carlson: None declared, Kelly Steed: None declared, Amanda Carapellucci: None declared, Joel Paschke: None declared, Lianne S. Gensler Grant/research support from: Pfizer, Novartis, UCB, Consultant of: AbbVie, Eli Lilly, GSK, Novartis, UCB

DOI: 10.1136/annrheumdis-2020-eular.6115

\section{AB1359-HPR PERCEPTION ABOUT FIBROMYALGIA AND ITS ACCOMPANYING SYMPTOMS AMONG MEXICAN PHYSICIANS}

R. I. Arvizu-Rivera ${ }^{1}$, N. Escobedo-Zuñiga ${ }^{1}$, I. J. Colunga-Pedraza ${ }^{2}$, G. SernaPeña ${ }^{2}$, A. Cárdenas ${ }^{2}{ }^{1}$ Hospital Universitario “Dr. Jose Eleuterio Gonzalez", Internal Medicine Department, Monterrey, Mexico; ${ }^{2}$ Hospital Universitario "Dr. Jose Eleuterio Gonzalez", Rheumatology Division, Monterrey, Mexico

Background: Previous studies showed that $93 \%$ of rheumatologists consider fibromyalgia (FM) as a clinical entity. However, accompanying symptoms such as fatigue, widespread pain, sleep disturbance and headache are underrecognized among physicians. According to a previous study, most recognized symptoms by general practitioners are fatigue and widespread pain $(72.6 \%)$, while about thirty percent of physicians recognize sleep disturbance and depression as symptoms Objectives: To investigate physicians' point of view of FM accompanying symptoms in northeastern Mexico.

Methods: We designed an electronic survey about physicians' perceived importance of depression, fatigue, widespread pain, sleep disturbances, headache and irritable bowel disease symptoms (pain and cramping) in patients with FM Questions were answered using a 5-point Likert scale: 1, strongly disagree; 2 disagree; 3 , neutral; 4, agree; 5 , strongly agree. General practitioners, rheumatologists, neurologists, psychiatrists were included.

Results: A total of 236 physicians were included: general practitioners, 149 (59.3\%); rheumatologists, 21 (8.9\%); neurologists 18 (7.6\%); psychiatrists 8 
(3.4\%), and family physicians, $49(20.8 \%)$. FM was considered a clinical diagnosis by $208(88.1 \%)$ and most physicians think FM is both a physical and psychological condition, 190 (80.5\%). Full results on physicians' perceptions is shown in Table 1. Fatigue was the symptom which most physicians agreed or strongly agreed was important in FM, 219 (92.7\%). Disagreement (any degree) was greater regarding abdominal pain/cramping being an important symptom in FM, 52 (22\%). Complete results can be seen in Image 1.

Table 1. Perceptions' of physicians about FM.

\begin{tabular}{lc}
\hline \multicolumn{1}{c}{ Variable } & \\
\hline $\mathrm{FM}$ is a clinic diagnostic, $\mathrm{n}(\%)$ & $208(88.1)$ \\
Unsure $\mathrm{FM}$ is a clinical diagnostic, $\mathrm{n}(\%)$ & $12(5)$ \\
$\mathrm{FM}$ is a physical illness, $\mathrm{n}(\%)$ & $33(14)$ \\
$\mathrm{FM}$ is a psychological illness, $\mathrm{n}(\%)$ & $11(4.7)$ \\
$\mathrm{FM}$ is both physical and psychological, $\mathrm{n}(\%)$ & $190(80.5)$ \\
$\mathrm{FM}$ has a negative impact on quality of life, $\mathrm{n}(\%)$ & $227(96.2)$ \\
FM has a negative impact on life expectancy, $\mathrm{n}(\%)$ & $135(57.2)$
\end{tabular}

Conclusion: FM was considered a clinical diagnostic and an illness both physical and psychological by most physicians. Headache and abdominal pain/cramping are symptoms less likely to be perceived as important in patients with FM. References:

[1] Perrot S, Choy E, Petersel D, et al. Survey of physician experiences and perceptions about the diagnosis and treatment of fibromyalgia. BMC Health Serv Res. 2012 Oct 10;12:356.

[2] Kianmehr N, Haghighi A, Bidari A. Are general practitioners well informed about fibromyalgia? Int J Rheum Dis. 2017 Dec;20(12):1917-1921

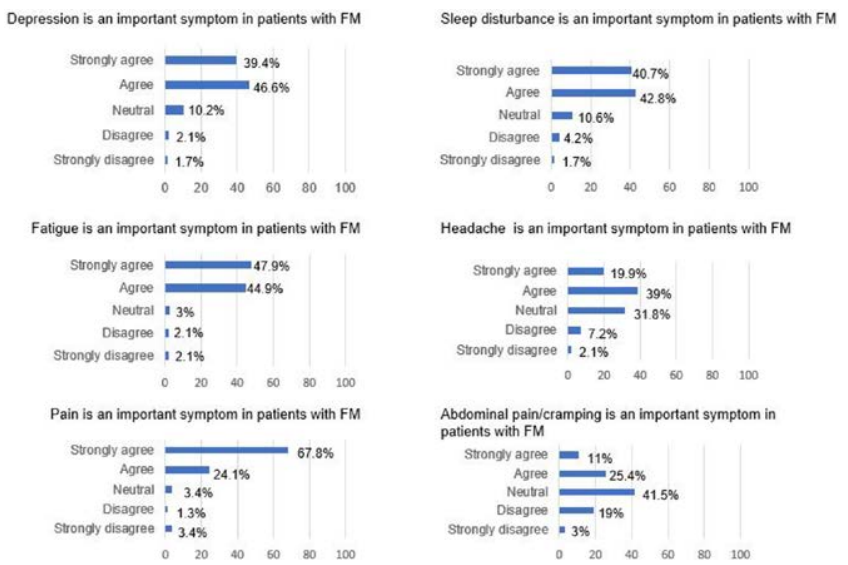

Figure 1. Image 1. Perception of accompanying symptoms of fibromyalgia (FM)

Disclosure of Interests: None declared

DOI: 10.1136/annrheumdis-2020-eular.4845

\section{AB1360-HPR A MODEL TO IMPROVE MINORITY PATIENT RECRUITMENT IN LUPUS CLINICAL TRIALS - THE AMERICAN COLLEGE OF RHEUMATOLOGY MIMICT PROJECT EXPERIENCE}

S. Sheikh ${ }^{1}$, N. Wanty ${ }^{2}$, S. Mccalla ${ }^{3}$, A. Santana ${ }^{1}$, S. Saxena Beem ${ }^{1}$, J. Walker ${ }^{1}$, D. Holt ${ }^{4}$, A. Howell ${ }^{4}$, K. Holtz ${ }^{2}$, S. Williams ${ }^{3}$, A. Anandarajah ${ }^{4}{ }^{1}$ University of North Carolina, Chapel Hill, United States of America; ${ }^{2} \mathrm{KDH}$ Research \& Communication, Atlanta, United States of America; ${ }^{3}$ American College of Rheumatology, Atlanta, United States of America; ${ }^{4}$ University of Rochester, Rochester, United States of America

Background: In the US, African Americans and Latinos are underrepresented in lupus clinical trials (LCTs), ${ }^{1}$ despite experiencing the greatest lupus disease burden. ${ }^{2,3}$ Low participation in LCTs results in inadequate data on treatment effectiveness for minority patients, and fewer opportunities for better care and treatment options. ${ }^{1}$ Only one percent of minority patients are referred to clinical trials each year. ${ }^{4}$ Provider barriers to making referrals include limited time and unfamiliarity with lupus and LCT opportunities. ${ }^{4}$ Using US fedral grant funds, the American College of Rheumatology (ACR) developed MIMICT, a two-part model with associated materials to address provider-side LCT referral barriers. The materials include a toolkit for clinical trial sites and an educational toolkit for providers.

Objectives: Our objectives are to:

-Describe the US LCTs disparities.

-Discuss the research methodology to evaluate the two-part MIMICT model.
-Assess the feasibility of the model to increase minority involvement in clinical trials.

Methods: We designed two studies to evaluate the MIMICT model.The first study used an online, pretest/posttest, two-group evaluation approach to assess the extent to which the educational toolkit increased providers' knowledge, attitudes, self-efficacy, and behavioral intentions to refer minority patients to clinical trial. We conducted the study in 2018 with primary care providers (PCPs) and again in 2019/2020 with speciality providers. The second study used a longitudinal, mised methods, case-study approach to explore the real-world use of the toolkits with clinical trial site teams at two university medical centers.

Results: In the first study,among MIMCT-exposed PCPs, mean scores indicated statistical significance at $\mathrm{p} \leq 0.001$ with more knowledge about referring [55.84 ( $\mathrm{sd}=23.51)$ vs $41.76(s d=19.98)$ ], more self-efficacy to refer [55.00 (sd=37.22) vs. 37.99 (sd=34.42)] and more intentions to refer [61.36 (43.85) vs. 33.41 (41.16)] African American patients to LCTs among the treatment group than the control group, respectively. This presentation will discuss additional data comparing the study in 2018 and the study in 2019/2020 and look comparatively at outcomes across provider type.

In the second study, we found that the driver for successful engagemetn of providers and their subsequent use of the educational toolkit was the development of a trusting relationship between the clinical trial site teams and providers in the community. The development of trust took repeated and varied modes of contact, which we will discuss in-depth.

Conclusion: The MIMICT educational toolkit increase knowledge, self-efficacy, and intentions to refer lupus patients to LCTs. However, building trust between LCT sites and local providers takes time and repeated outreach, but the potential benefits to medicine and minority health are substantial.

References:

[1] The Society for Women's Health Research. (2011). Dialogues on diversifying clinical trials: successful strategies for engaging women and minorities in clinical trials. Washington, DC: Food and Drug Administration, Office of Women's Health.

[2] Falasinnu, T., Chaichian, Y., Bass, M. B., \& Simard, J. F. (2018). The representation of gender and race/ethnic groups in randomized clinical trials of individuals with sytemic lupus erythematosus. Current Rheumatology Reports, 20(4)

[3] Pons-Estel, G. J., Alarcon, G. S., Scofield, L., Reinlib, L., \& Cooper, G. S (2010). Understanding the epidemiological progression of systemic lupus erythematosus. Seminars in Arthritis and Rheumatism, 39(4).

[4] Korieth, K. (2016). Engaging healthcare providers as research facilitators. The CenterWatch Monthly, 23, 1-5.

Disclosure of Interests: None declared

DOI: 10.1136/annrheumdis-2020-eular.654

\section{HPR Interdisciplinary research}

\section{AB1361-HPR PRIMARY CARE PHARMACOLOGICAL TREATMENT FOR PATIENTS WITH HAND ARTHRALGIA}

M. M. Castañeda-Martínez ${ }^{1}$, G. Figueroa-Parra ${ }^{1}$, D. Vega-Morales ${ }^{1}$, J. M. Calderón Espinosa ${ }^{1}$, B. R. Vázquez Fuentes ${ }^{1}$, J. A. Esquivel Valerio ${ }^{1}$, Y. G. Ordoñez Azuara ${ }^{2}$, D. Á. Galarza-Delgado'. 'University Hospital "Dr. José Eleuterio González", Rheumatology Service, Monterrey, Mexico; ${ }^{2}$ University Hospital "Dr. José Eleuterio González", Family Medicine Service, Monterrey, Mexico

Background: Primary care physicians (PCP) are the first point of contact for patients with a new-onset inflammatory rheumatic disease, like rheumatoid arthritis (RA). Consequently, primary care is crucial to the early diagnosis and prompt treatment of such individuals. The first three months following the onset of RA symptoms represent an important therapeutic window. Historically, patients with inflammatory arthritis received first-line treatment with non-steroidal anti-inflammatory drugs (NSAIDs), moving to synthetic disease-modifying anti-rheumatic drugs (DMARDs) relatively late in the disease process. As synthetic DMARDs are usually initiated in secondary care by rheumatologists, PCP focus on alleviation of patient's discomfort. Documented problems in primary care practice include accuracy of diagnosis, test ordering, medication use and delays in referral.

There is no evidence of which is the pharmacological treatment more commonly used for hand arthralgia in Family Medicine patients of a university hospital on their first or second visit.

Objectives: To examine the primary care physicians' pharmacological treatment prescribed for hand arthralgia in a Family Medicine Consultation.

Methods: In a period of a year and two months, eligible patients were recruited on their first or second visit to the Family Medicine Consultation of the Hospital Universitario "Dr. José Eleuterio González" in Monterrey, Nuevo León, México. Eligible patients were adults (aged $\geq 18$ years) with hand arthralgia as their chief complaint, who had not rheumatologic diagnosis and wasn't caused by trauma. Ninety patients were recruited, data were collected by capturing the prescription made by PCP. 